DOI:

УДК 621.785.5: 621.793.6

І.В. Кругляк, к.т.н., доц., докторант, seredabp@ukr.net

Дніпровський державний технічний університет, м. Кам’янське

\title{
МОДЕЛЮВАННЯ ПРОЦЕСУ ОТРИМАННЯ ПОКРИТТІВ В КОМПОЗИЦЙНИХ НАСИЧУЮЧИХ СЕРЕДОВИЩАХ
}

В роботі розглянуто формування захисних покриттів в композиіийних насичуючих середовищах відбувається при нестаціонарних температурних умовах. Температура, що змінюється в часі, спочатку за рахунок зовнішнього прогрівання, а потім за рахунок займання веде до того, що ні теплова, ні хімічна рівновага до повного закінчення процесу і охолодження продуктів неможлива. Швидкості протікання хімічних процесів визначаються кінетичними закономірностями, залежними як від температури, так і від дифузійних чинників. Проте, припускаючи, принаймні, на стадії прогрівання, щьо гальмування дифузійних прочесів газової фази невеликі, а швидкість зміни температури мала, в порівнянні зі швидкістю протікання газофазних хімічних реакиій, вважаємо, що кожному температурному значенню відповідає рівноважний склад продуктів. Тоді, розрахувавши рівноважний склад продуктів реакиії для ряда конкретних температур з діапазону ї̈ зміни, можна простерігати за хімічною картиною розвитку проиесу.

Ключові слова: композиійні насичуючі середовища; термодинаміка; моделювання; покриття.

The paper considers the formation of protective coatings in composite saturating media occurs under unsteady temperature conditions. The temperature changes in time, first due to external heating, and then due to ignition, which leads to the fact that neither thermal nor chemical equilibrium is possible until the process is complete and the products are cooled. The rates of chemical processes are determined by kinetic regularities, which depend both on temperature and diffuse factors. However, assuming, at least at the heating stage, that the inhibition of diffuse processes of the gas phase is small, and the rate of temperature change is small compared to the rate of flow of gas-phase chemical reactions, we assume that each temperature value corresponds to the equilibrium composition of the products. Then, having calculated the equilibrium composition of the reaction products for a number of specific temperatures from the range of its change, it is possible to prostrate according to the chemical pattern of the development process

Keywords: modeling; thermodynamics; synthesis; coatings; aluminum; titanium.

\section{Постановка проблеми}

Формування захисних покриттів в композиційних насичуючих середовищах відбувається при нестаціонарних температурних умовах. Температура, що змінюється в часі, спочатку за рахунок зовнішнього прогрівання, а потім за рахунок займання веде до того, що ні теплова, ні хімічна рівновага до повного закінчення процесу і охолодження продуктів неможлива. Швидкості протікання хімічних процесів визначаються кінетичними закономірностями, залежними як від температури, так і від дифузійних чинників. Проте, припускаючи, принаймні, на стадії прогрівання, що гальмування дифузійних процесів газової фази невеликі, а швидкість зміни температури мала, в порівнянні зі швидкістю протікання газофазних хімічних реакцій, вважаємо, що кожному температурному значенню відповідає рівноважний склад продуктів.

Тоді, розрахувавши рівноважний склад продуктів реакції для ряда конкретних температур з діапазону ії зміни, можна простерігати за хімічною картиною розвитку процесу.

\section{Аналіз останніх досліджень та публікацій}

У статті Кухаревої Н.Г., Галинської Н.А., Петрович С.Н. [1] при розгляді процесу формування дифузійних шарів зазвичай роблять спробу простежити за цим процесом, використовуючи діаграми стану сплавів. При цьому виходять 3 положення, що стало майже правилом, що формування шару на ізотермі дифузії йде за підвищенням концентрації дифундуючого елемен- 
ту в системі сплавів і підкоряється законам фазових перетворень. В цьому випадку спочатку повинні виникати фази нижчого складу, потім середнього i, нарешті, вищого (теорія чистої або атомної дифузії) [2]. Згідно іншої теорії (теорія реакційної дифузії) формування дифузійного шару може розпочинатися з утворення фази вищого або середнього складу, минувши стадію утворення фази нижчого складу, якщо термодинамічні умови для утворення цих фаз виявляться сприятливішими, ніж для фаз нижчого складу [3].

Наявний великий теоретичний і експериментальний матеріал [4-10], який грунтується на застосуванні прецизійних методів дослідження фазового і хімічного складів дифузійного шару, переконує нас в тому, що у багатьох випадках практики хіміко-термічної обробки утворення дифузійного шару не підкоряється рівноважним умовам, а протікає переривчасто і може розпочатися з утворення фази вищого або середнього складу. Структура дифузійного шару в цьому випадку не $\epsilon$ рівноважною. Серед різних чинників, що впливають на механізм формування дифузійного шару з нерівноважною структурою, головними є початкові умови, передуючі процесу дифузії елементів у метал, які прямо або побічно залежать від ряду фізико-хімічних і кінетичних чинників насичення, особливо значимих, якщо йдеться про багатокомпонентну систему насичення, представлену в цьому дослідженні.

3 виникненням теорії про нерівноважні системи з'явилася можливість впливати на структуру і властивості дифузійних шарів за рахунок зміни динаміки самого процесу насичення. Змінюючи склад середовища, що насичує, і співвідношення компонентів, що входять до неї, можна впливати на систему і тим самим змінювати кінетику дифузійних процесів.

\section{Формулювання мети досліджень}

Метою даної роботи $є$ фізико-хімічне моделювання формування покриттів, отриманих 3 використанням композиційних насичуючих середовищ

\section{Виклад основного матеріалу}

При дифузійному насиченні важливим $€$ перенесення компонентів до поверхні через газову фазу, що насичує [20]. Отримання захисних покриттів проводиться при нестаціонарних температурних умовах тому важливими є хімічні транспортні реакції, реалізація яких за рахунок газотранспортного агенту (ГТА) в порошкових сумішах, пов'язана 3 наявністю градієнтів температур. При цьому спостерігаються три основні взаємозв'язані реакції, характерні для усіх дифузійних покриттів [20]:

1. Реакції в середовищі, що насичує, коли утворюються активні атоми і відбувається їх дифузія до поверхні оброблюваного металу.

2. Реакції на межі фаз, коли відбувається адсорбція активних атомів, що утворилися, поверхнею насичення. При хемосорбції відбувається взаємодія між атомами елементу, що насичує, і оброблюваної поверхні, яке за своїм характером близько до хімічного.

3. Дифузія і накопичення атомів усередині металу. При накопиченні атомів дифундуючого елементу на поверхні насичення виникає дифузійний потік від поверхні углиб металу, що обробляється. Процес можливий тільки за умови розчинності дифундуючого елементу в металі і досить високої температури, що забезпечує необхідну енергію атомам. Можливість здійснення хімічного транспорту в хвилі горіння грунтується на тому, що в процесі горіння відбувається послідовна зміна температурних режимів і температура в кожній точці суміші пробігає ряд безперервних значень від $\mathrm{T}_{0}$ до $\mathrm{T}_{\mathrm{r}}$. Таким чином, для отримання покриттів може бути використаний нестаціонарний температурний процес, поєднаний з хімічними транспортними реакціями.

Вибір оптимального складу шихти для проведення процесу отримання захисних покриттів при нестаціонарних температурних умовах проводили на підставі результатів досліджень теплової картини процесу і фізико-механічних властивостей захисних покриттів, таких

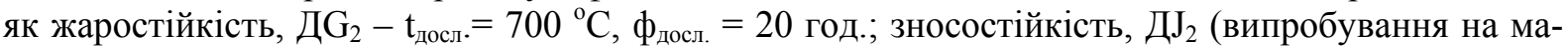

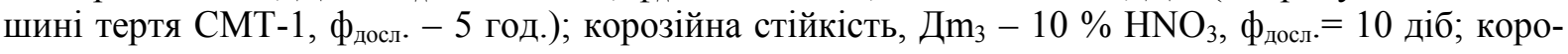
зійна стійкість, Д的 $4-10 \% \mathrm{H}_{2} \mathrm{SO}_{4}, \phi_{\text {досл. }}-10$ діб. При використанні як постачальник кремнію крем'яниста складова були проведені наступні випробування фізико-механічних властивостей:

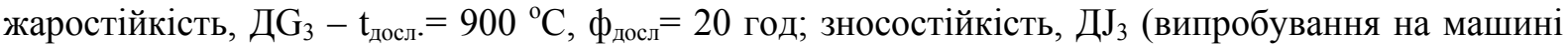
тертя СМТ-1, досл. $_{\text {д }} 5$ год); корозійна стійкість, Д- $\mathrm{m}_{5}-30 \% \mathrm{HCl}, \phi_{\text {досл. }}=10$ діб; корозійна стійкість, Дат $6-10 \% \mathrm{H}_{2} \mathrm{SO}_{4}, \phi_{\text {досл. }}-10$ діб. 
Для отримання композиційних насичуючих порошкових шихт був проведений повний факторний експеримент $2^{3}$, в якому основними факторами були: хромиста складова, кремній, а також один з легуючих елементів таких як алюміній, бор, титан, вольфрам.

Матриця планування експериментів і розрахункові рівні інтервалів варіювання для отримання порошкових шихт, використовуваних в режимі теплового самозаймання наведені в табл. 1.

Таблищя 1. Результати регресійного аналізу експериментальних даних

\begin{tabular}{|c|c|c|c|c|c|c|c|c|}
\hline \multirow{3}{*}{$\begin{array}{c}\text { Параметр } \\
\text { Коефіцієнти } \\
\text { регресії }\end{array}$} & \multicolumn{8}{|c|}{ Функції відгуку } \\
\hline & \multicolumn{2}{|c|}{$Y_{1}$} & \multicolumn{2}{|c|}{$\mathrm{Y}_{2}$} & \multicolumn{2}{|c|}{$\mathrm{Y}_{3}$} & \multicolumn{2}{|c|}{$\mathrm{Y}_{4}$} \\
\hline & $\begin{array}{l}Д m_{3} \\
10^{-1} \\
\Gamma / \mathrm{M}^{2}\end{array}$ & $\begin{array}{c}\text { Д } \mathrm{m}_{5,} \\
10^{-1} \Gamma / \mathrm{M}^{2}\end{array}$ & $\begin{array}{c}\text { ДЈ }_{2} \\
10^{-1} \Gamma\end{array}$ & $\begin{array}{c}\text { ДЈ }_{3}, \\
10^{-1} \Gamma\end{array}$ & $\begin{array}{c}\operatorname{Lm}_{4,} \\
10^{-1} \Gamma / \mathrm{M}^{2}\end{array}$ & $\underset{10^{-1} \Gamma / \mathrm{m}^{2}}{Д \mathrm{~m}_{6}}$ & $\begin{array}{c}\text { ДG }_{2,} \\
10^{-4} \mathrm{M}^{2}\end{array}$ & $\begin{array}{l}\text { Д } \mathrm{G}_{3,} \\
10^{-4} \Gamma / \mathrm{M}^{2}\end{array}$ \\
\hline $\mathrm{b}_{0}$ & 85 & 32,025 & 104,75 & 76,375 & 192,125 & 221,25 & 170 & 169,8750 \\
\hline$b_{1}$ & $-9,75$ & $-2,6250$ & $-9,75$ & $-7,785$ & $-19,625$ & -13 & $-19,5$ & $-14,125$ \\
\hline $\mathrm{b}_{2}$ & $-6,5$ & $-1,8250$ & $-7,25$ & $-8,625$ & $-15,875$ & $-8,75$ & -12 & $-8,125$ \\
\hline $\mathrm{b}_{3}$ & $-7,25$ & $-1,200$ & $-6,75$ & $-9,6250$ & $-6,3750$ & -12 & $-6,75$ & $-8,625$ \\
\hline$b_{12}$ & 0,25 & $-0,1750$ & $-0,25$ & $-0,8750$ & $-2,1250$ & 1,5 & $-1,5$ & $-0,1250$ \\
\hline$b_{13}$ & 3 & 0,25 & 3,25 & $-1,875$ & 2,8750 & 1,25 & $-2,25$ & $-5,6250$ \\
\hline$b_{23}$ & $-1,25$ & 0,25 & $-0,25$ & 1,3750 & 1,1250 & -1 & $-0,23$ & $-0,1250$ \\
\hline$b_{123}$ & $-1,5$ & 0,55 & 0,25 & 4,125 & $-1,1250$ & $-4,25$ & 2,25 & 0,875 \\
\hline $\begin{array}{c}\text { Розрахункові } \\
\text { значення } \\
\text { критерію } \\
\text { Кохрена, } \mathrm{G}_{\mathrm{p}}\end{array}$ & 0,3507 & 0,3429 & 0,3416 & 0,3448 & 0,3502 & 0,3451 & 0,3542 & 0,3517 \\
\hline $\begin{array}{c}\text { Табличні } \\
\text { значення } \\
\text { критерію } \\
\text { Кохрена, } \mathrm{G}_{\mathrm{T.}}\end{array}$ & 0,316 & 0,516 & 0,316 & 0,516 & 0,316 & 0,516 & 0,316 & 0,516 \\
\hline 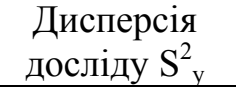 & 4,3033 & 0,49 & 5,3033 & 3,62 & 7,6033 & 12,33 & 6,5033 & 13,7433 \\
\hline $\begin{array}{c}\text { Величини } \\
\text { значимих } \\
\text { коефіцієнтів } \\
\end{array}$ & $\geq 3,1559$ & $\geq 1,0649$ & $\geq 3,5035$ & $\geq 2,8959$ & $\geq 4,1950$ & $\geq 5,3428$ & $\geq 4,3030$ & $\geq 5,6399$ \\
\hline $\begin{array}{c}\text { Розрахун- } \\
\text { кові значен- } \\
\text { ня критерію } \\
\text { Фішера, } F_{\text {розр. }}\end{array}$ & 4,787 & 1,4469 & 3,2432 & 10,2392 & 3,2223 & 2,9676 & 3,06 & 3,7764 \\
\hline $\begin{array}{c}\text { Табличні } \\
\text { значення } \\
\text { критерію } \\
\text { Фишера, } \\
\text { Fтабл. } \\
\end{array}$ & 19,3 & 19,3 & 19,3 & 19,3 & 19,3 & 19,3 & 19,3 & 19,3 \\
\hline $\begin{array}{c}\text { Коефіцієнт } \\
\text { множинної } \\
\text { кореляції }\end{array}$ & 0,98 & 0,99 & 0,99 & 0,97 & 0,97 & 0,98 & 0,99 & 0,99 \\
\hline
\end{tabular}

В результаті регресійного аналізу були отримані ряд рівнянь, що показують залежність фізико-механічних властивостей захисних покриттів від вмісту кремнію, хромистої складової, крем'янистої складової, бору, титану і вольфраму.

Без урахування статично незначимих коефіцієнтів були отримані наступні рівняння: 


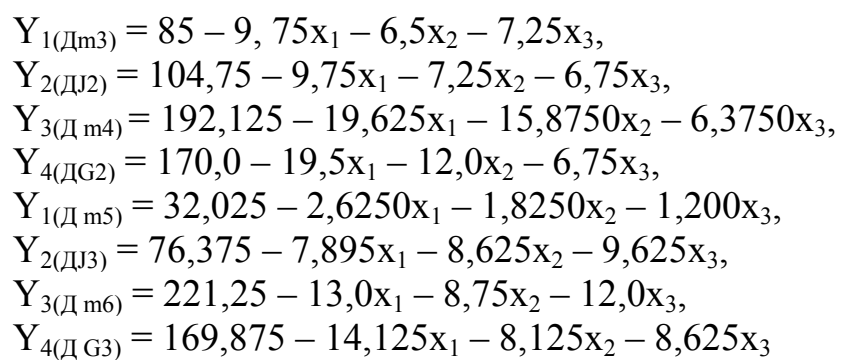

Перевірка адекватності моделей показує, що їх можна використати для прогнозування значень функцій відгуку при будь-яких значеннях чинників, що знаходяться між верхнім і нижнім рівнями.

Для оцінки адекватності отриманих рівнянь був проведений розрахунок по отриманих рівняннях регресії. Результати розрахунків були зіставлені з експериментальними дослідженнями. Як видно з табл. 2, похибка між розрахунковими і експериментальними значеннями функції відгуку не перевищує 5\%, що свідчить про правильність розрахункової моделі.

Таблиця 2. Відношення розрахункових і експериментальних даних для оптимальних складів

\begin{tabular}{|c|c|c|c|}
\hline Показник & $\begin{array}{c}\text { Розрахункове зна- } \\
\text { чення }\end{array}$ & $\begin{array}{c}\text { Експериментальне зна- } \\
\text { чення }\end{array}$ & Похибка, \% \\
\hline$Д \mathrm{~m}_{3}$ & 61,5 & 62 & 0,08613 \\
\hline$Д \mathrm{~J}_{2}$ & 81,02 & 84 & 3,33 \\
\hline$Д \mathrm{~m}_{4}$ & 150,375 & 151 & 0,414 \\
\hline$Д \mathrm{G}_{2}$ & 131,75 & 130 & 1,328 \\
\hline$Д \mathrm{~m}_{5}$ & 26,375 & 27,3 & 3,388 \\
\hline$Д \mathrm{~J}_{3}$ & 50,251 & 53 & 5,187 \\
\hline$Д \mathrm{~m}_{6}$ & 187,5 & 185 & 3,333 \\
\hline$Д \mathrm{G}_{3}$ & 139 & 134 & 3,597 \\
\hline
\end{tabular}

3 метою визначення складів порошкових шихт, які використовують в режимі теплового самозаймання, оптимальних фізико-механічних властивостей, що забезпечують отримання: зносостійкості, корозійної стійкості, жаростійкості, з використанням отриманих регресійних рівнянь, будували 3-х мірні графічні залежності: "вміст елементів - властивості" (рис. 1). Значення корозійної стійкості, жаростійкості, тим вище, чим більше значення хромистої і крем'янистої складових, вольфраму і титану. Зносостійкість вища, чим більше вмісту хромистої складової і бору. Найкраще поєднання експлуатаційних характеристик захисних покриттів, отримано в сумішах, які містять \% мас.: 15-26 ХC; $15 \mathrm{KpC}$; 7,5-8 Si; $10 \mathrm{~B} ; 25 \mathrm{Ti} ; 15 \mathrm{~W}$ i $6 \mathrm{Al}$.

Процес формування захисних покриттів в режимі горіння можна представити в наступному виді: На І стадії - стадії прогрівання, за рахунок підпалу шихти фронт реакції проходить відстань, яка дорівнює зоні прогрівання. За проміжок часу $\left(0-\phi_{1}\right)$ покриття не утворюється. Відбувається дифузія пари йоду і хлору з шихти в зону прогрівання. Пари йоду і хлору реагують в цій фазі з кремнієм, алюмінієм, хромом, відновленим з окислу, і утворюються з'єднання $\mathrm{SiCl}_{2}, \mathrm{SiCl}_{3}, \mathrm{SiCl}_{4}, \mathrm{CrCl}_{2}, \mathrm{CrCl}_{3}, \mathrm{CrCl}_{4}, \mathrm{SiI}, \mathrm{SiI}_{3}, \mathrm{SiI}_{4}, \mathrm{AlI}, \mathrm{AlI}_{2}, \mathrm{AlI}_{3}$. На II стадії - стадії тепловиділення, відбувається розкладання йодидів і хлоридів на поверхні. За рахунок високого хімічного потенціалу, що зумовлений градієнтом концентрації, починає сформуватись дифузійне покриття, що має б - фазу ( $\mathrm{Fe}_{3} \mathrm{Si}$ и $\left.\mathrm{Fe}_{3} \mathrm{Al}\right)$. На III стадії - стадії охолодження, велике значення грає швидкість охолодження, яка характеризується критерієм Вi [11-13]:

$$
\mathrm{Bi}=\frac{\mathrm{aS}}{\lambda},
$$




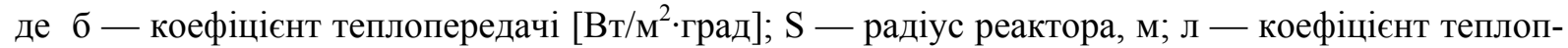
ровідності [Вт/м• град].

У цей період відбувається остаточне формування дифузійного покриття.

На відміну від режиму горіння режим теплового самозаймання здійснюється шляхом нагрівання реактора зовнішнім джерелом тепла. Режим самозаймання реалізовуватиметься у тому випадку, якщо характерний час зовнішнього нагріву буде більше характерного часу реактора, як цілого. На І стадії - стадії інертного прогрівання основна термічна реакція не протікає. Шихта за час від 0 до ф1 прогрівається до температури самозаймання ( $\left.\mathrm{t}^{*}\right)$. Дифузійне покриття ще не формується. На ІІ стадії - стадії теплового самозаймання відбувається основна екзотермічна реакція і підйом температури від $t^{*}$ до $t_{\max }$ iз швидкістю $100-300$ град/c. За час $\left(\phi_{1}-\phi_{2}\right)$ починають утворюватися галогеніди алюмінію, кремнію, бору, титану, вольфраму. На III стадії відбувається падіння температури до температури силіціювання, за рахунок відбору тепла деталями. За час $\left(\phi_{2}-\phi_{3}\right)$ починає формуватися $6-$ фаза. На IV стадії - стадії ізотермічної витримки $\left(\phi_{3}-\phi_{4}\right)$ формується захисне покриття. Тривалість цієї стадії визначає різну товщину дифузійних покриттів. На відміну від стаціонарних режимів, товщина покриття значно вища через те, що аустеніт, що утворюється при швидкісному нагріванні при нестаціонарних температурних умовах, характеризується підвищеною щільністю дислокації, дрібнозернистістю і дрібноблочністю. В результаті цього процес дифузійного насичення протікає більш інтенсивно, як це спостерігається при швидкісному електронагріванні. На V стадії - (стадії охолодження - $\phi_{5}$ ) покриття формується більше повільно, за рахунок падіння температури. Зі збільшенням швидкості охолодження загальний час формування дифузійного покриття зменшується [14-19].

\section{Висновки та перспективи подальших досліджень}

В результаті фізико-хімічного моделювання встановлено, що процес отримання захисних покриттів можливий тільки за умови розчинності дифундуючого елементу в металі і досить високої температури, що забезпечує необхідну енергію атомам. Можливість здійснення хімічного транспорту в хвилі горіння грунтується на тому, що в процесі горіння відбувається послідовна зміна температурних режимів і температура в кожній точці суміші пробігає ряд безперервних значень від $\mathrm{T}_{0}$ до $\mathrm{T}_{\mathrm{r}}$. Таким чином, для отримання покриттів може бути використаний нестаціонарний температурний процес, поєднаний з хімічними транспортними реакціями.

\section{Список використаної літератури}

1. Кухарева Н.Г. Исследование физико-механических свойств боридных покрытий на углеродистых сталях / Н.Г. Кухарева, Н.А. Галынская, С.Н. Петрович // Наука - образованию, производству, экономике: материалы 11-й Международной научно-технической конференции. Т. 1. - Минск: БНТУ. - 2013. - С. 371

2. Лахтин Ю.М. Физические основы процесса азотирования / Ю.М. Лахтин. - М.: Машгиз, 1948. - $144 \mathrm{c}$.

3. Бугаков В.3. Диффузия в металлах / В.З. Бугаков. - Л.; М.: ГИТТЛ, 1949. - 212 с.

4. Кухарева Н.Г. Борирование углеродистых и легированных сталей в кипящем слое / Н.Г. Кухарева, С.Н. Петрович, Н.А. Галынская, В.Ф. Протасевич, Т.Н. Смирнова // Наука и техника: международный научно-технический. - 2012. - № 5. - С. $8-12$.

5. Кухарева Н.Г. Влияние условий термодиффузионной карбонитрации и структуры диффузионных покрытий на механические свойства инструментальной стали Р6М5 / Н.Г. Кухарева, С.Н. Петрович, Н.А. Галынская // Вестник Белорусского национального технического университета: научно-технический журнал. - 2009. -№ 4. - С. 25-29.

6. Гальнсккая Н.А. Исследование износостойкости боридных покрытий, полученных из композиционных порошковых сред / Н.А. Галынская, Н.Г. Кухарева, С.Н. Петрович, Т. Бабуль, 3. Обухович // Наука и техника: международный научно-технический журнал. - 2012. - № 1. - C. $10-16$ 
7. Гальнская Н.А. Особенности технологии получения комплексных диффузионных покрытий на основе бора и хрома / Н.А. Галынская // Перспективы развития поверхностного и объемного упрочнения сплавов: сборник научных трудов, посвященный 40-летию кафедры "Материаловедение в машиностроении" / под ред. Ворошнина Л.Г; БНТУ. Минск, 2004. C. $48-52$.

8. Галынская Н.A. Особенности формирования боридных покрытий из композиционных металлотермических порошковых сред / Н.А. Галынская, Н.Г. Кухарева, В.С. Нисс, С.Н. Петрович // Вестник Белорусского национального технического университета: научнотехнический журнал. - 2011. - № 4. - С. 15-20.

9. Галынская Н.А. Сравнительный анализ характеристик диффузионных слоев, полученных в «кипящем» слое и при традиционном печном нагреве / Н.А. Галынская, Г.В. Стасевич / Наука - образованию, производству, экономике: материалы 11-й Международной научнотехнической конференции. Т. 1. - Минск : БНТУ, 2013. - С. 372.

10. Гальнская Н.А. Упрочняющая обработка штампов для глубокой вытяжки / Н.А. Галынская, Н.Г. Кухарева, С.Н. Петрович, Г.В. Стасевич // Вестник Белорусского национального технического университета: научно-технический журнал. 2010. - №4. - С. 30-34.

11. Лыков А.В. Теория теплопроводности. М. : Высш.шк., 1967. - С. 599.

12. Лыков А.В. Тепломассообмен. Справочник. М. : Энергия, 1972. - С. 560.

13. Середа Б.П. Поверхневе зміцнення матеріалів. /Середа Б.П., Калініна Н.С., Кругляк І.В. Монографія, Запоріжжя : ЗДІА, 2004. - 230 с.

14. Середа Б.П. Физико-механические свойства многокомпонентных силицированных покрытий, полученных в нестационарных температурных условиях СВС-систем / Середа Б.П., Кругляк И.В., Бойко М.А., Жеребцов А.А. // Сборник докладов 6-й Междунар. конф. «Оборудование и технологи и термической обработки металлов и сплавов». - Харьков. 2005. - Часть III. - C. 255-256.

15. Середа Б.П. Повышение износо- и коррозионной стойкости деталей оборудования металлургических предприятий. / Середа Б.П., Кругляк И.В., Михайлин В.М., Кругляк Д.О // Металургія: Збірник наукових праць: - Вип. 2 (30) - Запоріжжя, ЗДІА. - 2014. - 196 с., C. $146-153$.

16. Середа Б.П. Получение хромоалитированных покрытий на углеродистых материалах в у словиях самораспространяющегося высокотемпературного синтеза. /Середа Б.П., Кругляк И.В., Белоконь Ю.А., Середа Д.Б. // Строительство, материаловедение, машиностроение: Сборник науч. трудов. Вып.48. Ч.1 / Под общ. ред. проф. В. И. Большакова. Днепропетровск: Приднепровская гос. академ. стр-ва и архит. - 2015. - 296-300 с.

17. Середа Б.П. Комбіноване деформування матеріалів з інтерметалідним хоромоалітованим покриттям, отриманим в умовах саморозповсюджувального високотемпературного синтезу / Середа Б.П., Кругляк И.В., Белоконь Ю.А. // Обработка материалов давлением: сборник научных трудов. - Краматорск: ДГМА, - № 1 (40), - 2015. - С. 103-107.

18. Середа Б.П. Отримання зносостійких силіційованих покритті для деталей автотранспортної техніки сільськогосподарського призначення. / Середа Б.П., Кругляк І.В., Кочнева О.В. Коровкін А.А. //Актуальні задачі сучасних автотехнологій. Тернопільський національнотехнічний університет ім. Івана Пулюя. ТНТУ, Тернопіль. - 2017 - С. 44-45.

19. Кругляк И.В. Получение многокомпонентных силицированных покрытий в режиме горения СВС-систем / Кругляк И.В., Кругляк Д.О., Середа Д.Б. // Сб. научных работ «Перспективные технологии и приборы» Луцк : Луцкий НТУ.-2017.-№10(1). - С. 89-98.

20. Термическая обработка в машиностроении: Справочник под ред. Ю.М. Лахтина, А.Г. Рахштадта. - М.:Машиностроение. 1980. - 783 с. 


\title{
MODELING OF COATING PROCESS IN COMPOSITE SATURATED POWDERS Kruglyak I.V.
}

\begin{abstract}
At diffusion saturation, it is important to transfer components to the surface through the gas phase, which saturates [20]. Production of protective coatings is carried out under non-stationary temperature conditions. Chemical transport reactions are important. Their realization is due to the presence of temperature gradients due to the gas transporting agent (GTA) in powder mixtures. In this case, there are three main interrelated reactions characteristic of all diffuse coatings [20]:

Reactions in the medium, saturates when active atoms are formed and their diffusion to the surface of the metal being processed.

Reactions at the phase boundary, when the adsorption of active atoms formed by the saturation surface occurs. When chemisorption occurs, the interaction between the atoms of the element saturates and the surface being treated, which by its nature is close to chemical.

Diffusion and accumulation of atoms inside the metal. With the accumulation of atoms of a diffusing element on the surface of saturation, a diffuse flow from the surface into the metal is processed. The process is possible only under the condition of the solubility of the diffusing element in the metal and a sufficiently high temperature that provides the necessary energy to the atoms. The possibility of chemical transport in the combustion waves is based on the fact that during the combustion process, a successive change of temperature regimes occurs and the temperature at each point of the mixture runs through a series of continuous values from $\mathrm{T} 0$ to $\mathrm{Tg}$. Thus, to obtain coatings, a nonstationary temperature process combined with chemical transport reactions can be used. To obtain composite powder saturation charges, a full factorial experiment was conducted in which the main factors were: the chromium component, silicon, and also one of the alloying elements such as aluminum, boron, titanium, and tungsten. In order to determine the composition of powder blends, which are used in the thermal self-ignition mode, the optimal physicomechanical properties, which provide: wear resistance, corrosion resistance, heat resistance, using the obtained regression equations, built 3-D graphical dependencies: "element content - properties" (Fig. 1). The value of corrosion resistance, heat resistance, the higher, the greater the value of chromium and siliceous components, tungsten and titanium. Wear resistance is higher, the higher the chromium content of the component and boron. The best combination of performance characteristics of protective coatings, obtained in mixtures containing\% wt.: 15-26 XC; 15 cattle; 7.5 - $8 \mathrm{Si} ; 10 \mathrm{~V} ; 25 \mathrm{Te} ; 15 \mathrm{~W}$ and $6 \mathrm{Al}$.
\end{abstract}

\section{References}

[1] Kuhareva N.G. Study of the physicomechanical properties of boride coatings on carbon steels / N.G. Kukhareva, N.A. Galynskaya, S.N. Petrovich // Science - education, production, economics: materials of the 11th International Scientific and Technical Conference. T. 1. - Minsk: BNTU. 2013. - p. 371

[2 Lakhtin Yu.M. The physical basis of the process of nitriding / Yu.M. Lakhtin. - M .: Mashgiz, 1948. - 144 with.

[3] Bugakov V.Z. Diffusion in metals / V.Z. Bugakov. - L.; M .: Hittl, 1949. - 212 p.

[4] Kukhareva N.G. Boronization of carbon and alloyed steels in a fluidized bed / N.G. Kukhareva, S.N. Petrovich, N.A. Galynskaya, V.F. Protasevich, T.N. Smirnova // Science and technology: international scientific and technical. - 2012. - № 5. - p. 8-12.

[5] Kukhareva N.G. Influence of thermal diffusion carbonitration conditions and diffusion coating structures on the mechanical properties of R6M5 tool steel / N.G. Kukhareva, S.N. Petrovich, N.A. Galynskaya // Bulletin of the Belarusian National Technical University: scientific and technical journal. - 2009. - № 4. - p. 25-29.

[6] Galynskaya N.A. Study of wear resistance of boride coatings obtained from composite powder media / N.A. Galynskaya, N.G. Kukhareva, S.N. Petrovich, T. Babul, Z. Obukhovich // Science and Technology: an international scientific and technical journal. - 2012. - № 1. - p. 10-16 
[7] Galynskaya N.A. Features of technology for producing complex diffusion coatings based on boron and chromium / N.A. Galynskaya // Prospects for the development of surface and bulk hardening of alloys: a collection of scientific papers dedicated to the 40th anniversary of the department "Materials Science in Mechanical Engineering" / ed. Voroshnina L.G .; BNTU. Minsk, 2004. pp. 48-52.

[8] Galynska N.A. Features of the formation of boride coatings from composite metal-thermal powder media / N.A. Galynskaya, N.G. Kukhareva, V.S. Niss, S.N. Petrovich // Bulletin of the Belarusian National Technical University: scientific and technical journal. - 2011. - № 4. - p. 15-20.

[9] Galynskaya N.A. Comparative analysis of the characteristics of diffusion layers obtained in the "fluidized" layer and with traditional furnace heating / N.A. Galynskaya, G.V. Stasevich / Science - education, production, economy: materials of the 11th International Scientific and Technical Conference. T. 1. - Minsk: BNTU, 2013. - p. 372.

[10] Galynskaya N.A. Hardening processing of dies for deep drawing / N.A. Galynskaya, N.G. Kukhareva, S.N. Petrovich, G.V. Stasevich // Bulletin of the Belarusian National Technical University: scientific and technical journal. 2010. - №4. - p. 30-34.

[11] Lykov A.V. Theory of heat conduction. M.: Higher., 1967. - p. 599.

[12] Lykov A.V. Heat and mass transfer. Directory. M.: Energy, 1972. - p. 560.

[13] Sereda B.P. Verhneve zmitsnennya materiv. / Sereda B.P., Kalinina N.C., Kruglyak I.V. Monographs, Zaporizhzhya: ZDIA, 2004. - $230 \mathrm{p}$.

[14] Sereda B.P. Physicomechanical properties of multicomponent siliconized coatings obtained under unsteady temperature conditions of SHS systems / Sereda B.P., Kruglyak I.V., Boyko M.A., Zherebtsov A.A. // Collection of reports of the 6th Intern. conf. "Equipment and technology and heat treatment of metals and alloys." - Kharkov. - 2005. - Part III. - p. 255-256.

[15] Sereda B.P. Improving the wear and corrosion resistance of equipment parts of metallurgical enterprises. / Sereda B.P., Kruglyak I.V., Mikhaylin V.M., Kruglyak D.O. // Metallurgiya: Zbirnik naukovih prats: - Vip. 2 (30) - Zaporizhzhya, ZDIA. - 2014. - 196 s., - p. 146-153.

[16] Sereda B.P. Production of chromo-catalyzed coatings on carbon materials in self-propagating high-temperature synthesis. / Sereda B.P., Kruglyak I.V., Belokon Yu.A., Sereda D.B. // Construction, materials science, mechanical engineering: Collection of scientific. works. Issue 48. Part 1 / Under total. ed. prof. V.I. Bolshakov. - Dnipropetrovsk: Pridneprovsk State. Academic pages and archit. -2015 . $-296-300 \mathrm{p}$.

[17] Sereda B.P. Combined deformation of materials from intermetallic hormonal pokrittyam, created in the minds of samorozpovsyuzhuvalnogo high temperature synthesis / Sereda B.P., Kruglyak IV, Belokon Yu.A. // Processing materials by pressure: a collection of scientific papers. Kramatorsk: DGMA, - № 1 (40), - 2015. - p. 103-107.

[18] Sereda B.P. Otrimannya znosostiykih silitsiyovanih pokritti for parts of motor transport tehniki silskogospodarskogo priznachennya. / Sereda B.P., Kruglyak I.V., Kochneva O.V. Korovkin A.A. // Actual problems of the current autotechnology. Ternopil National Technical University im. Ivan Puluy. TNTU, Ternopil. - 2017 - p. 44-45.

[19] Kruglyak I.V. Production of multicomponent siliconized coatings in the combustion mode of SHS systems / IV Kruglyak, DO Kruglyak, DB Sereda // Sat. scientific works "Perspective technologies and devices" Lutsk: Lutsk NTU. - 2017. - №10 (1). - WITH. 89-98.

[20] Thermal processing in mechanical engineering: Reference book under the editorship of Yu. M. Lakhtin, AG G. Rahstadt.-M.: Mechanical Engineering. 1980. - 783 c. 